\title{
Artigos
}

\section{As interfaces da avaliação na Educação Infantil}

Resumo: O presente artigo debate sobre a temática da avaliação na Educação Infantil e as implicações que esse processo traz ao direito das crianças em viver suas infâncias. Apresentamos a concepção de Educação Infantil, infância e criança, na qual nos aportamos, assim como, um breve histórico do processo de avaliação na Educação Infantil, no momento em que esta, torna-se primeira etapa da Educação Básica. Discutiremos a avaliação como processo inerente à educação das crianças e que, dado a conjuntura política atual, tal processo pode implicar negativamente no direito das crianças viverem a infância ao terem precocizados os processos de aprendizagem pela lógica da escolarização. Desta forma, apresentamos a avaliação de contexto, atualmente estudada por especialistas da área, como um contraponto a avaliações externas e em larga escala.

Palavras-chave: Avaliação em larga escala. Avaliação de Contexto. Educação Infantil. Infância.

\section{The interfaces of evaluation in early childhood education}

Abstract: This article discusses the theme of evaluation in Early Childhood Education and the implications that this process brings to the right of children to live their childhoods. We present the conception of Early Childhood Education, childhood and child, in which we contribute, as well as a brief history of the evaluation process in Early Childhood Education, in the moment it becomes the first stage of Basic Education. We will discuss evaluation as a process inherent in the education of children and, given the current political conjuncture, this process may negatively imply the right of children to live their childhood by anticipated the learning processes by the logic of schooling. Therefore, we present the context assessment, currently studied by specialists in the field, as a counterpoint to external and large-scale evaluations.

Keywords: Large-scale evaluation. Context Evaluation. Childhood Education. Childhood.

\footnotetext{
1 Doutora em Educação pela Universidade Federal de Santa Catarina. Supervisora Escolar da Rede Municipal de Ensino de Florianópolis. E-mail: josalazardecastro@gmail.com

2 Mestre em Educação pela Universidade Federal de Santa Catarina. Supervisor Escolar da Rede Municipal de Ensino de Florianópolis. E-mail: fabriciozs2014@gmail.com
} 
O propósito central do presente artigo é debater sobre a temática da avaliação na Educação Infantil e as implicações que esse processo traz ao direito das crianças em viverem suas infâncias. Para tanto, iniciaremos esse diálogo definindo a concepção de Educação Infantil, na qual nos aportamos. Visando romper monólogos e ideias adultocêntricas nos contextos em que as crianças pequeninas (bebês e crianças pequenas e bem pequenas ${ }^{3}$ ) estão inseridas, por meio do conceito bakhtiniano de dialogismo, compreendemos esta etapa da Educação Básica, como uma esfera educacional que se constitui por diferentes momentos históricos que implica em um constante diálogo com diferentes áreas do conhecimento. Oconceito de dialogismo é definido pelo confronto de vozes e entonações, alternadas entre os sujeitos do discurso por meio de suas enunciações. A enunciação é o elo na cadeia discursiva, forma réplicas que tornam o diálogo inacabado, vinculando valores ideológicos que ligam diferentes consciências (BAKHTIN, 2015). Desta forma, torna-se necessário compreender as particularidades das crianças pequenas em diálogo com seus processos de socialização em que se constituem por uma trama relacional, mas com particularidades diferentes dos adultos. Nesse sentido, procura-se perceber que elas "finalmente, possuem modos diferenciados de interpretação do mundo e de simbolização do real, que são constitutivos das "culturas da infância", as quais se caracterizam pela articulação complexa de modos e formas de racionalidade e de acção" (SARMENTO, 2005, p.371).

Entendemos como importante a busca por referenciais que formulem definições da função social da instituição formal de Educação Infantil (KRAMER, 2006). Não obstante, que privilegie a concepção de criança compreendendo-a como ativa e potencialmente capaz de participar dos processos educativos do qual faz parte (BARBOSA, 2000; BONDIOLI, 1993; FARIA, 1999; ROCHA, 1999;) e evidencia a infância como condição viva, que se modifica historicamente e conforme o contexto social na qual encontra-se inserida (CORSARO, 2011; FERREIRA, 2005; QVORTRUP, 2010; SARMENTO, 2005).

Esses elementos são constitutivos da definição de Educação Infantil, como instituição formal de educação, que se caracteriza pelo dialogismo entre os sujeitos que dela fazem parte, principalmente as crianças, como locutoras e interlocutoras dessa rede relacional. Compreender a importância da criança como ponto de partida para a organização e efetivação dos processos pedagógicos, exige ainda mais dos/as professores/as como profissionais responsáveis desse processo educativo. Como menciona Mello (2007), "o professor é um intelectual" e cabe a ele a responsabilidade pelos processos de humanização da criança, desde muito cedo, quando ela é inserida nos espaços de educação formal.

No lugar da criança que era incapaz de aprender até atingir naturalmente determinado nível de desenvolvimento, encontramos uma criança capaz desde que nasce de, na

\footnotetext{
${ }^{3}$ Seguimos a orientação de Barbosa (2010) para a definição das crianças na Educação Infantil por grupo-etário.
} 
atividade social mediada pelo adulto - por parceiros mais experientes - estabelecer relações com o outro e com o mundo que se apresenta a ela. No entanto, aprendemos também que a criança aprende de maneira diferente do adulto e de maneira diferente em cada idade, deste ponto de vista, temos procurado compreender as especificidades do aprender, ou seja, as formas pelas quais a criança se relaciona com o mundo e aprende em cada idade. (MELLO, 2007, p. 92)

A compreensão de que a criança possui modos diferentes de se apropriar do conhecimento, das situações cotidianas e até das mais complexas, como diferente do modo como nós adultos nos apropriamos, é convergente com a ideia de criança potencialmente ativa (SARMENTO, 2005). Daí a premissa de que não é possível estabelecer padrões de aprendizagem e desenvolvimento, pois compreendemos que cada criança, cada sujeito, é único e estabelece interações com o mundo de modo relacional, mas também individual.

Eis a importância de termos clareza sobre essas diferenças, compreendendo-as como caminho para romper com a ideia de criança como sinônimo de incompletude, compreendendo que em cada momento, nos primeiros anos de vida, existem regularidades biológicas que definem os modos de apreensão e compreensão do mundo entre elas. Porém, essas regularidades não são determinantes por si só, mas podem perfeitamente serem potencializadas pela circunscrição social do ambiente em que se encontra a criança (VIGOTSKI, 1996).

Diante do exposto, discutiremos a seguir a avaliação na Educação Infantil como um dos processos imbricados com a aprendizagem e o desenvolvimento inerentes à educação das crianças e que, dado a conjuntura política atual, pode implicar em um retrocesso no direito das crianças à infância, uma vez que pode haver uma precocização da escolarização nesta etapa da Educação Básica.

\section{Breve contextualização histórica da implantação da avaliação na Educação Infantil}

A educação de zero a cinco ${ }^{4}$ anos ao ser legitimada no sistema de ensino pela Constituição Federal (C. F.) de 1988 e a Lei de Diretrizes e Bases da Educação Nacional (LDBEN) de 1996, inclui aspectos inerentes ao sistema educacional, como a avaliação, por exemplo. No inciso I do Artigo 31 da LDBEN (BRASIL, 1996) é indicado que a avaliação na Educação Infantil será “mediante acompanhamento e registro do desenvolvimento das crianças, sem o objetivo de promoção, mesmo para o acesso ao ensino fundamental". Com a criação da Lei no 12.796 de 20135, essa redação é mantida, mas incluída no conjunto de outras quatro regras comuns, preconizando a organização e funcionamento das instituições educativas. Como podemos observar, nos incisos II, III, IV e V do mesmo Artigo 31, da citada Lei.

II - carga horária mínima anual de 800 (oitocentas) horas, distribuída por um mínimo de 200 (duzentos) dias de trabalho educacional;

${ }^{4}$ Optamos por definir a Educação Infantil compreendida entre a idade de zero a cinco anos, dado a legislação atual. Ver: BRASIL. Constituição (1998). Emenda constitucional n 59/2009, de 11 de novembro de 2009. Diário Oficial [da] República Federativa do Brasil, Poder Executivo, Brasília, DF, 12 nov. 2009.

5 Disponível em: http://www.planalto.gov.br/CCIVIL_03/leis/L9394.htm Acessado em 04/09/2015 
III - atendimento à criança de, no mínimo 4 (quatro) horas diárias para o turno parcial e de 7 (sete) horas para a jornada integral;

IV - controle de frequência pela instituição de educação pré-escolar, exigida a frequência mínima de $60 \%$ (sessenta por cento) do total de horas;

$\mathrm{V}$ - expedição de documentação que permita atestar os processos de desenvolvimento e aprendizagem da criança.

Tais determinações da LDBEN, concernente à avaliação na Educação Infantil, demonstram que essa etapa da Educação Básica vem assumindo cada vez mais aspectos inerentes ao sistema educacional de outros níveis de educação. A educação formal das crianças de zero a cinco anos, incluída na Educação Básica, adota processos intrínsecos à organização educativa (escolar) como regulamentação dessa primeira etapa da educação. A regulamentação da Educação Infantil em forma de Lei é importante como previsão à garantia de que esta seja assumida formalmente como educação, desvencilhando-a de outros setores, como os de cunho assistencialistas, por exemplo. Ao mesmo tempo, presume-se que o atendimento nessas instituições se dê por profissionais com formação adequada para tal, assegurando às crianças, atendimento voltado às particularidades da pequena infância.

A partir de 2011 o Instituto Nacional de Estudos e Pesquisas Educacionais Anísio Teixeira (INEP) em parceria com o Ministério da Educação (MEC) articulou diversas organizações educacionais e movimentos sociais, tais quais: a Associação Nacional de Pós-Graduação e Pesquisa em Educação (ANPED), Associação Nacional pela Formação dos Profissionais da Educação (ANFOPE), Associação Brasileira de Avaliação Educacional (ABAVE), Confederação Nacional dos Trabalhadores em Educação (CNTE), Movimento Interfóruns de Educação Infantil do Brasil (MIEIB), Rede Nacional da Primeira Infância (RNPI) e União Nacional dos Dirigentes Municipais de Educação (UNDIME) que, em parceria com pesquisadores de várias universidades objetivaram "propor uma política nacional de avaliação da educação infantil" (Portaria MEC no 1747, de 16 de dezembro de 2011). Esta denominada Avaliação Nacional da Educação Infantil (ANEI) (FREITAS 6 , 2017).

O propósito dessa política consistia na construção de uma avaliação voltada aos contextos educacionais e tratadas como processo formativo para os diferentes agentes que atuam nos espaços da Educação Infantil, tal qual a avaliação de contexto, difundida na Itália (BONDIOLI e FERRARI, 2004; BONDIOLI; SAVIO, 2013). Este movimento procurava considerar diferentes particularidades do processo educativo que envolve a aprendizagem e o desenvolvimento da criança, assim como o aprimoramento das práticas pedagógicas e das relações estabelecidas entre os diferentes sujeitos que constituem a comunidade educativa. Além de buscar garantir que as crianças possam ter assegurado seu direito de viver a infância com mais plenitude.

\footnotetext{
${ }^{6}$ Ao abordar, neste artigo, fontes relacionadas a um blog, nos pautamos em Evangelista (2009) que apresenta consistentes subsídios teórico-metodológicos para sustentar que documentos de política educacional podem circular em diferentes e diversos suportes entre os quais: leis, documentos oficiais e oficiosos, dados estatísticos, documentos escolares, correspondências, livros de registros, regulamentos, relatórios, livros, textos e correlatos. Ou seja, para esta autora todo tipo de registro histórico é compreendido como documento, por exemplo: fotos, diários, arte, música, entrevistas, depoimentos, filmes, jornais, revistas, sites, entre outros compõe a base empírica de uma pesquisa, neste caso aquele destinado à difusão de diretrizes políticas para a educação, sendo analisado como fonte primária. É pertinente destacar que Luiz Carlos de Freitas é Livre Docente desde 1996 e atualmente é professor titular da Faculdade de Educação da Universidade Estadual de Campinas/UNICAMP. Atua na área da Educação, com ênfase em Avaliação da Aprendizagem e de Sistemas. Com inúmeras publicações científicas, tem escolhido nos últimos anos expressar suas ideias e elaborações, resultantes de pesquisas, também em blog de sua própria autoria.
} 
No ano de 2016, em 5 de maio, o Governo Federal, sob o comando de Dilma Vana Rousseff, durante seu segundo mandato presidencial (2015/2018), assina a Portaria MEC no 369. Tal documento é publicado no dia subsequente no Diário Oficial da União (DOU) no 86, Seção 1, p. 26 e passa a instituir o Sistema Nacional de Avaliação da Educação Básica (SINAEB) que contemplava a ANEI como uma das avaliações constitutivas dessa política educacional.

Entretanto, com o afastamento do exercício da função de Presidenta do país, em 12 de maio de 2016, por 180 dias, em decorrência do processo de impeachment ${ }^{7}$, por meio da usurpação do cargo presidencial pelo então Vice-Presidente Michel Miguel Elias Temer Lulia que a posteriori passa a ocupar o cargo de Presidente do país com o apoio do Congresso Nacional. Assim, em 25 de agosto de 2016 ocorre a revogação do SINAEB por meio da Portaria MEC no 981/16 publicada no DOU no 165, Seção 1, p. 16. Tal fato acarreta na anulação de toda a normatização sobre a ANEI que fora até então produzida desde o ano de 2011, bem como as discussões para implementação decorrentes dela, na avaliação dos processos educativos na Educação Infantil (FREITAS, 2017).

Com a revogação do SINAEB presenciamos uma interrupção das atividades e dos processos de discussão que vinham ocorrendo desde 2011. A própria normatização acerca da ANEI torna-se diretamente atingida com a revogação da Portaria MEC nº 981/16. Este movimento político, no qual vive a educação brasileira, em que políticas públicas educacionais buscam na avaliação um meio de acelerar a aprendizagem das crianças, vêm ao encontro da lógica gerencial e empresarial, por resultados, discutida por Souza (2015). Para o autor,

No Estado gerencial, a autonomia e a avaliação são os elementos chave no processo educacional, para que ocorra o controle dos resultados na educação. Esse movimento já vinha sendo delineado pelos organismos multilaterais desde os anos 2000. Com nuances um pouco diferente, mas complementares, as recomendações do Banco Mundial (BM) e da Unesco mostram os elementos estruturantes dos modelos de Gestão Centrada na Escola. (SOUZA, 2015, p. 66)

A crítica realizada pelo autor se estabelece em relação à avaliação centrada individualmente no sujeito e "consubstanciada no trabalho". Isto traduz-se em conformidade da classe trabalhadora, "levada a cabo pelas classes dominantes, diretamente ligada à manutenção da sociabilidade baseada na desigualdade", aspectos que mantém a dominação da elite sobre as decisões políticas do país, disfarçada por um discurso de "ajuste social via educação" (ZANARDINI, 2014, p. 75). Estes aspectos se aproximam do que temos visto em relação à destituição da ANEI, dando lugar a uma nova (velha) lógica de avaliação que foca no sujeito, individualmente, tornando-o unicamente o responsável pelo seu sucesso ou não profissional, desde muito pequeno, ainda na Educação Infantil. Segundo Freitas: "a realização da ANEI é uma demanda da sociedade brasileira, tendo em vista a necessidade de se ter informações sobre a

\footnotetext{
${ }^{7}$ Forças políticas, jurídicas e midiáticas de centro-direita e conservadores se unem em torno da destituição de uma Presidenta eleita democraticamente, com o objetivo de retomar o poder, sem que tenha sido comprovado, crime de responsabilidade que estivesse respaldado constitucionalmente, contra esta Presidenta. Portanto, tal ação que o país presencia é representação de uma forma arbitrária de tomada do Governo.

${ }^{8}$ Exerceu a Presidência do país provisoriamente entre 12 de maio de 2016 a 31 de agosto de 2016. A partir dessa data assume a função presidencial e deve permanecer até a conclusão do mandato em 31 de dezembro de 2018.
} 
qualidade da Educação Infantil com vistas a oferecer às crianças brasileiras uma escolarização inicial de qualidade" (2017, s/p).

Nas últimas décadas, vêm sendo redefinidas novas formas de governo e de gestão educativa, expressas em políticas de descentralização e avaliação como estratégias para tornar a educação mais eficiente e eficaz e, assim, supostamente aumentar a qualidade das instituições de educação. Esse processo de descentralização dá vazão à avaliação em larga escala, como reguladoras e medidoras dos índices de desempenho das crianças, formando a ideia de serem indispensáveis para melhorar a qualidade da Educação Infantil. Nesse sentido, as autoras Souza; Moro; Coutinho (2015) ao discutirem sobre a avaliação como um ato de qualidade, contrariam a lógica da avaliação individual, assinalando que este processo para ser efetivamente aliado à busca da qualidade institucional, precisa estar relacionado ao contexto educativo e não ao sujeito individualmente.

A discussão que fazemos no presente documento parte da consideração do contexto educativo como objeto de avaliação. Por contexto educativo nos referimos ao conjunto de aspectos que determinam o tipo de experiência educativa (formativa) que a instituição de Educação Infantil oferece às crianças e seus familiares, como por exemplo, a qualidade do ambiente físico, relacional e social, as experiências educativas propostas, a organização do trabalho entre os docentes, as relações com as famílias, as atividades e os relacionamentos profissionais, entre outros. (SOUZA; MORO; COUTINHO, 2015, p. 27) (grifos das autoras)

A inferência deste grupo de especialistas, na área da Educação Infantil, resulta de um processo avaliativo $^{9}$ que diferentes municípios brasileiros, em parceria com algumas universidades públicas vivenciaram. Este movimento formativo, efetivado, especialmente a partir do ano de 2011, apoiado pelo MEC, teve consultoria externa das professoras Anna Bondioli e Donatella Savio da Università di Pavia (It). Um dos objetivos deste percurso era implementar a avaliação de contexto como contraponto às avaliações em larga escala. No entanto, com as alterações ocorridas no ano de 2016, este percurso é interrompido, mas não se apagam as pesquisas realizadas por estudiosos da área da Educação Infantil que já sinalizavam esta modalidade avaliativa como uma possibilidade de analisar as instituições educativas por dentro, a partir do próprio contexto e dos diferentes sujeitos que dela fazem parte.

A seguir, apresentaremos o modo como a avaliação na Educação Infantil vem sendo, atualmente, encaminhada por meio de políticas públicas educacionais. Tais encaminhamentos parecem ferir o direito das crianças à aprendizagem pelas interações, pela brincadeira e pelas múltiplas linguagens, como meio de apropriação e ampliação dos repertórios culturais, na promoção de suas potencialidades.

9 O referido processo avaliativo resulta de um Projeto intitulado "Formação da Rede em Educação Infantil: Avaliação de Contexto" para a política nacional de avaliação em Educação Infantil. O projeto é uma ação da Universidade Federal do Paraná com outras universidades brasileiras (Universidade Federal de Minas Gerais, Universidade Federal do Rio de Janeiro e Universidade do Estado de Santa Catarina), além da universidade italiana - UniversitàdeglistudidiPavia/ltália - e conta com a parceria técnica e financeira da Secretaria de Educação Básica do Ministério da Educação." (SOUZA; MORO; COUTINHO, 2015) 


\section{Em busca de contrapontos}

Estudos recentes acerca da avaliação na Educação (MORO, 2016; MORO; SOUZA, 2014; NEVES; MORO, 2013;) fazem menção à avaliação de modo integrado a um conjunto de outros elementos, como a observação, o registro e a documentação pedagógica na Educação Infantil. Dessa forma, é possível afirmar que a partir do ano 2009 houve um significativo crescimento na produção científica acerca desses aspectos na Educação Infantil, com grande enfoque à abordagem italiana de educação. Consideramos que esse movimento está imbricado aos dispositivos legais que regulamentam a obrigatoriedade da avaliação individual das crianças matriculadas em instituição de Educação Infantil (BRASIL, 2009). As pesquisas produzidas se configuram como resistência à concepção e a avaliação comportamentalista e classificatória. Além de produzirem debates e propostas de negação à lógica de avaliações externas, dissociadas do contexto social e cultural dos sujeitos partícipes das instituições educativas.

Estudos como de Moro (2016); Moro e Souza (2014), Neves e Moro (2013) e Correa e Andrade (2011) criticam as avaliações em larga escala que desconsideram as particularidades contextuais, sociais e culturais dos sujeitos e das instituições nas quais são aplicadas. Esse grupo de autoras, por exemplo, evidenciam as lacunas do instrumento americano de avaliação utilizado pela rede municipal de ensino do Rio de Janeiro, Ages and Stages Questionnaires (ASQ-3) ${ }^{10}$. Ao analisarem as propostas apresentadas pela Secretaria de Assuntos Estratégicos (SEA) de 2011, Correa e Andrade (2011) veem como um retrocesso as proposições acerca da avaliação das crianças na Educação Infantil, principalmente, em relação às orientações advindas de documentos anteriores, sobre esse processo, ferindo inclusive os direitos das crianças.

[...] se o que se deseja é melhorar o desenvolvimento integral da criança, a proposta de avaliá-la individualmente, e não as suas condições de vida e educação, significa, além de um equívoco e de um desrespeito à legislação em vigor, um grande retrocesso diante do que já se constituiu até o momento para a infância brasileira. (CORREA e ANDRADE, 2011, p. 285)

Já Neves e Moro (2013) apresentam considerações sobre a avaliação na Educação Infantil, indicando a necessidade de avanços sobre o debate no processo de avaliação interna, dentro das instituições educativas. As autoras constatam que as práticas educativas e a concepção das professoras sobre a criança, se evidenciam ainda mais nos momentos de avaliação. Assinalam por fim, que é necessária a busca por referenciais teóricos que embasem modos de avaliação que contribuam com a prática pedagógica e respeitem as crianças como sujeitos de direitos, assim como abarquem "a consideração da infância como essencial à formação humana" (NEVES e MORO, 2013, p. 298). Nessa discussão, as autoras criticam as avaliações externas que usam métodos de medição para avaliar a criança e reforçam a concepção de que tal processo deve estar a serviço da qualificação do trabalho pedagógico. Devendo ainda, envolver todos os sujeitos da relação educativa, possibilitando a reflexão sobre o que é feito, como caminho para uma maior consciência do que propor como significativo às crianças.

10 Maiores esclarecimentos acerca desse instrumento encontram-se em RIO DE JANEIRO (Cidade). Secretaria Municipal de Educação. Manual de uso do ASQ-3. Guia rápido para aplicação do ASQ-3. Rio de Janeiro: SME, 2010. 
Igualmente, Moro e Souza (2014) discutem a avaliação na Educação Infantil como “integrante/partícipe” no debate a respeito da política e qualidade na educação, buscando "identificar o lugar da avaliação no campo da produção mais ampla sobre a educação infantil” (p. 109). Para as autoras, esse tema está diretamente relacionado ao mote da avaliação educacional, discussão que, segundo elas, se intensifica a partir dos anos de 1970, com a criação dos Programas de Pós-Graduação no Brasil. Outro destaque apontado pelas autoras, refere-se às pesquisas dos anos 2000, acerca do tema avaliação, que enfatizam críticas ao movimento de avaliação em larga escala nos anos de 1990, principalmente na Educação Básica, a partir dos anos iniciais.

Recentemente, Moro (2016) aponta que a avaliação deve vir ao encontro de análises que busquem a qualidade na educação, de modo contextualizado à realidade da instituição, primando pela análise dos serviços ofertados e não pela avaliação padronizada da criança. A autora afirma encontrar-se entre

[...] os especialistas em educação que, ao discutirem a avaliação na área, defendem investigações e análises acerca da oferta de serviços para a pequena infância em lugar da avaliação das crianças com instrumentos e procedimentos padronizados “quantificativos" e descontextualizados" (MORO, 2016, p. 06).

Desse percurso investigativo, as autoras Souza e Moro (2014), chegam ao tema da avaliação na Educação Infantil111, observando haver um acréscimo dessa discussão, em teses e dissertações, a partir de 2003 e ainda com maior representatividade a partir de 2008. Evidenciam ainda, existir pouca produção acadêmica sobre a avaliação das crianças nos espaços internos de Educação Infantil. No entanto, ressaltam que acreditam haver uma grande discussão a esse respeito nesses espaços, destacando que,

[...] a concepção de avaliação como uma prática que permite à instituição educativa refletir sobre si, sobre sua identidade, verificando e consolidando consensos acerca de seu próprio projeto; a ênfase ao caráter formativo da avaliação de determinado contexto, o que potencializa a criação de percursos de melhorias, em detrimento do juízo final acerca dos resultados. (MORO e SOUZA, 2014, p. 122)

Esses estudos vêm ao encontro da nossa discussão, uma vez que possibilita-nos compreender que concepções de avaliação têm permeado os debates teóricos e nos aproximam, em algum modo, do que é reverberado nas instituições educativas. Vinculada à concepção de avaliação está a concepção de criança, de infância, de Educação Infantil e de prática pedagógica.

A prática pedagógica deve ser realizada por profissionais com formação específica, uma vez que, não cabe a realização de fazeres com base no entretenimento e na ocupação do tempo, envolvendo as crianças para permanecerem seguras e protegidas até o momento de suas famílias lhes buscarem. É necessário que a prática pedagógica se realize pautada em fundamentos teóricos que sustentem a promoção do conhecimento, das descobertas, que ampliem a imaginação e enriqueçam de cultura, arte e afetos a vida das crianças desde sua inserção na Educação Infantil. A avaliação é parte desse processo, é

11 Para maiores esclarecimentos sobre essa trajetória acessar 0 artigo aqui citado em: http://www.fcc.org.br/pesquisa/publicacoes/eae/arquivos/1928/1928.pdf Acessado em 03/09/2015. As autoras também apresentam os autores que realizaram pesquisas sobre a temática da avaliação, que elas puderam localizar, assim como os instrumentos de avaliação localizados nas pesquisas. 
resposta do que propomos, é caminho de descoberta sobre os interesses das crianças diante do que vimos organizando e possibilitando a elas.

Segundo as DCNEI: "As instituições de Educação Infantil devem criar procedimentos para acompanhamento do trabalho pedagógico e para a avaliação do desenvolvimento das crianças, sem objetivo de seleção, promoção ou classificação" (BRASIL, 2009, p. 29). Essa redação vem ao encontro do que já determinara a LDBEN 9394 em 1996, mencionada anteriormente.

Todavia, nas DCNEI (BRASIL, 2009) são elencadas indicações de como o processo avaliativo deva ocorrer, ou seja, pautado em quais estratégias metodológicas. É ressaltada a importância da observação atenta às crianças, às transitoriedades e continuidades dos processos de aprendizagem delas. Também é apontada a necessidade de elaboração de formas de documentação, possibilitando a interação das famílias e de profissionais, que venham a acompanhar as crianças em anos sucessivos.

A avaliação seria ainda voltada aos "processos de desenvolvimento e aprendizagem da criança na Educação Infantil”, com atenção a não retenção das crianças em grupos específicos ou em relação ao ensino fundamental, uma vez que não é classificatória (BRASIL, 2009, p. 29). No entanto, nesse documento não é feito menção à importância da documentação pedagógica como forma de avaliar o próprio trabalho pedagógico, das professoras individualmente e em grupo (como recurso autoavaliativo) e como meio de historicizar o vivido na instituição, buscando caminhos para qualificar o trabalho coletivo, tendo como preocupação primeira, a criança.

O processo de formação em serviço está sempre relacionado à "avaliação de contexto", uma avaliação que deve se estabelecer na cotidianidade do fazer docente, ou seja, na própria observação das crianças e na percepção de quando e como participar de seus agires relacionais. Essa perspectiva de avaliação se define para Savio $(2013$; 2011) como promoção do interno, como processo democrático envolvendo os diferentes atores sociais do contexto educativo, é uma avaliação que facilita o compartilhamento de conhecimentos e experiências.

Sabemos, portanto, que esse processo de compreender a prática pedagógica pelo viés do compartilhamento, não ocorre de modo natural, nem por imposição, necessita de formação e tempo. Mas acima de tudo, de inícios, de tentativas para que se possa efetivar práticas diferenciadas, envolvendo os sujeitos que fazem parte da relação no contexto educativo. Esse processo, uma vez iniciado, permite reflexões mais aprofundadas e críticas sobre o trabalho realizado.

No entanto, esse procedimento precisa envolver o coletivo de profissionais, ser assumido como e no projeto político pedagógico, como diretriz para a formação continuada. Moro e Souza (2014, p. 105) corroboram com essa perspectiva ao afirmarem que “a avaliação não deve ser tratada ou desenvolvida de forma isolada, mas sim como processo constitutivo do processo educativo em sua amplitude, ambos inseridos no projeto político pedagógico da instituição". É justamente aqui que reside nossa preocupação em relação à revogação do SINAEB, afetando a Avaliação Nacional da Educação Infantil (ANEI) - uma esfera importante deste Sistema Nacional - e dando vasão à implantação da avaliação em larga escala e "quantificadora” como aponta Moro (2016). 
Em estudo recente, Castro (2016) discutiu a importância de se compreender os aspectos pedagógicos, inseparáveis da avaliação na Educação Infantil, entendendo que esse processo é abrangente e processual e não pode ser dissociado do planejar intencionalmente, do observar, do refletir e do registrar. De igual modo, está vinculado a outros recursos metodológicos, tais como a observação atenciosa e as escolhas do que registrar do cotidiano vivido pelas crianças. Tal organização requer a escolha de ferramentas e estratégias para que o registro possa ser feito sistematicamente, com finalidade pedagógica. A autora indica que o modo como se documentam esses dados, possibilita maior compartilhamento entre os sujeitos envolvidos no contexto educativo, dando visibilidade ao que transcorre no interior desses cotidianos, como ação fundamental da docência na Educação Infantil.

[...] não existem modelos a serem seguidos sem as devidas contextualizações do que as crianças revelam e sem a reflexão sobre se o que estamos propondo e ofertando a elas corresponde às suas expectativas e desejos de conhecer. Dessa forma, a avaliação tem muito mais sentido quando assumida em uma perspectiva dialógica, em que, ao avaliarmos a criança no conjunto contextual do que ela vivencia no espaço coletivo da Educação Infantil, estamos compreendendo esse processo como respostas às nossas práticas. (CASTRO, 2016, p. 91)

A observação, o registro e a avaliação são partes constitutivas do ato docente, assim torna-se necessário que o foco desse processo, ainda que dirigido à criança, seja revertido em reflexão e análise da prática pedagógica. Ter clareza de como significamos os modos de agir das crianças em relação à prática pedagógica pode caracterizar atenção ao modo como concebemos as crianças de pouca idade pelos seus fazeres. A criança é o sujeito principal, a quem devemos estar com o olhar e as proposições direcionadas, a partir do que ela se nos revela como interessante de vivenciar e experimentar. Porém a responsabilidade organizativa desse processo é de nós adultos (profissionais), mas sempre de modo compartilhado com as famílias e outros atores sociais integrados à instituição, assegurando-se, inclusive, a efetiva participação das crianças, nas escolhas do que preferem e indicam como relevante (CASTRO, 2016).

Desta forma, a avaliação pensada por agentes externos e implementada de modo regulatório aos processos de ensino e aprendizagem das crianças, na primeira infância, torna-se incoerente e fere a autonomia das instituições em constituírem seus modos próprios de conhecer seus limites e possibilidades, visando a superação dos desafios que se interpõem no cotidiano educativo. Souza (2015) afirma que a autonomia e a avaliação são os elementos chave no processo educacional, porém, dentro desta lógica, existe uma "pseudoautonomia" que concede a ideia de que, por meio de avaliações externas, as instituições educativas seriam auto gerenciáveis, quando na verdade, são reguladas por Organismos Internacionais, tendo como principal controlador, o Estado (CONTRERAS, 2002).

Para Contreras (2002) essas políticas educacionais transformam a autonomia em cumprimento de tarefas burocratizadas que não colaboram com a elaboração de um projeto político pedagógico que tenha como premissa encontros e discussões para tomada de decisões coletivas, que envolvam, de fato, a comunidade educativa, a saber, diretor/a, equipe pedagógica, professores/as, crianças, famílias e demais profissionais. 
As políticas educacionais que não explicitam seus principais objetivos precisam ser problematizadas, como forma de tornar o coletivo da instituição educativa capaz de criar ações de resistência e enfrentamento ao que essas políticas propõem. Isto, portanto, exige encontros entre a comunidade educativa, discussão e reflexão sobre os processos educacionais, é nesse sentido que vimos na avaliação de contexto uma possibilidade de contrapor a política de avaliação externa e classificatória voltada às crianças na Educação Infantil.

\section{Algumas considerações}

Neste texto apresentamos brevemente a concepção de Educação Infantil, criança e infância, na qual nos aportamos para realizar uma reflexão acerca das políticas públicas educacionais no que concerne à avaliação nesta etapa da Educação Básica. Nosso objetivo central foi problematizar as diferentes facetas da avaliação na Educação Infantil como processo que implica no direito das crianças de se apropriar do conhecimento historicamente produzido pela humanidade, sem que com isto, elas tenham interrompido, o direito à infância.

Apresentamos que a avaliação na Educação Infantil vem se constituindo como um processo histórico inerente ao momento em que esta passa a ser a primeira etapa da Educação Básica. Logo apresentamos as atuais mudanças nas políticas públicas educacionais, no cenário nacional, e, as implicações que vem ocasionando no processo de avaliação para as crianças na primeira infância. À luz de estudiosos da área, compreendemos que a avaliação de contexto pode ser um importante contraponto às demandas externas que a revogação do SINAEB, conjuntamente com as atividades que envolviam a avaliação na Educação Infantil - antes como um processo formativo e contextual - pode acarretar às crianças pequenas, aos professores/as, demais profissionais e instituições educativas.

A avaliação de contexto se caracteriza diferentemente das demais modalidades avaliativas por não se dirigir aos sujeitos individualmente (crianças, professores, demais profissionais). Se dirige, por sua vez, à realidade particular e aos sujeitos pertencentes aquele contexto educativo, levando em consideração os níveis organizativos dos diferentes espaços (planejamento, organização espacial e temporal, rotinas, oferta de elementos, brinquedos e etc.), da instituição em um todo (regimentos, Projeto Político Pedagógico, relatórios, memoriais, etc.) à legislação municipal, estadual e nacional (BONDIOLI e FERRARI, 2004).

Esta perspectiva de avaliação visa, especialmente, buscar a garantia da qualidade do interior das instituições de Educação Infantil, possibilitando reflexões a partir das experiências pedagógicas realizadas nos contextos educativos, em particular. Desta forma, pode-se encontrar pontos de partida que subsidiem a condução formativa dos profissionais (professores/as, demais profissionais, coordenação pedagógica e direção). Esta proposta de avaliar e refletir as práticas educacionais e pedagógicas, contribuem para que esse processo seja vivenciado do interior da instituição "promuoveredall'interno" como definem Bondioli e Ferrari 
(2004). Tal aspecto pode elevar as condições individuais e coletivas na compreensão das necessidades de mudanças e aprofundamentos acerca do que, cotidianamente, acontece nos espaços formais de educação.

A consolidação da avaliação de contexto na Educação Infantil sugere aprofundar as temáticas emergidas da prática pedagógica, na relação direta com as crianças, sujeitos principais do processo educativo, formando uma "consciência pedagógica" (Bondioli, 1993) nos/as professores/as, na busca de práticas que garantam um standard de qualidade. Este processo de avaliação constitui-se como processo dialógico vinculado aos demais procedimentos educativos, o planejar, observar, registrar e documentar - recursos que representam a materialização dos acontecimentos vivenciados no cotidiano - capaz de elucidar as condições para uma avaliação voltada ao percurso que a instituição educativa vem trilhando. Nesse sentido, o objetivo central da avaliação de contexto, não é o resultado final, mas o processo pedagógico, vivenciado cotidianamente em uma rede relacional, com diferentes sujeitos que compõem os espaços da Educação Infantil, a saber, crianças, profissionais com diferentes funções, família e comunidade.

Nossa intenção foi debater acerca das implicações da avaliação da Educação Infantil e das crianças na primeira infância como forma de refletir sobre a conjuntura atual das políticas educacionais. Entendemos, portanto, que a avaliação de contexto, pode ser uma ferramenta metodológica para aprofundar o conhecimento acerca dos processos educacionais na primeira etapa da educação Básica. No entanto, não pode ser assumida como um modelo único a ser seguido, mas sim como um contraponto à lógica das avaliações externas e em larga escala, nas quais não correspondem aos contextos educacionais e não se aproximam da realidade dos sujeitos participantes das instituições, que na sua diversidade, não podem ser avaliados por padrões específicos e reguladores.

\section{Referências}

BONDIOLI, Anna. Fisionaomia e storia di un gruppo di gioco. In: BONDIOLI, Anna. Far finta

insieme. Condizione, dinamiche, strategie. Quaderni Infanzia. Bergamo, Itália: Junior S.R.L., 1993.

BONDIOLI, Anna; FERRARI, Monica. Educare la professionalità degli operatori per l'infanzia. QuaderniInfanzia. Bergamo, Itália: Junior S.R.L., 2004.

BAKHTIN, Mikhail Mikhailovich. Problemas da poética de Dostoiévski. 5 ed. Revista. Trad. Paulo Bezerra. Rio de Janeiro, Forense Universitária, 2015.

BARBOSA, Maria Carmem Silveira. As especificidades da ação pedagógica com os bebês. Porto Alegre, 2010. 16f. Disponível em:

http:/ / portal.mec.gov.br/index.php?Itemid=1096\&id=15860\&option=com_content\&view=articule. $>$. Acesso em: 09 de jul. 2015 
Por amor e por força: as rotinas na Educação Infantil. Tese (doutorado) - Universidade Estadual de Campinas, Faculdade de Educação. Campinas: 2000.

BONDIOLI, Anna; SAVIO, Donatella (Orgs.). Participação e qualidade em educação da infância: percursos de compartilhamento reflexivo em contextos educativos. Tradução: Luiz Ernani Fritoli.

Curitiba: UFPR, 2013.

BRASIL. Ministério da Educação. Conselho Nacional de Educação. Resolução CNE/CEB n. ${ }^{\circ}$ 5/2009, de 17 de dezembro de 2009. Fixa as Diretrizes Curriculares Nacionais da Educação Infantil. Diário Oficial [da] República Federativa do Brasil, Poder Executivo, Brasília, 18 dez. 2009a, Seção 1, p. 18.

BRASIL. Lei de Diretrizes e Bases da Educação Nacional. Lei nº 9394/1996, de 20 de dezembro de 1996. Diário Oficial [da] República Federativa do Brasil, Poder Executivo, Brasília, DF, 23 dez. 1996, p. 27833.

BRASIL. Ministério da Educação. Portaria n 1747, de 16 de dezembro de 2011. Brasília, DF, 2011.

BRASIL.Constituição (1988). Constituição da República Federativa do Brasil de 1988. Disponível em: <http://www.planalto.gov.br/ccivil_03/Constituicao/Constituicao.htm >. Acesso em: 26 nov. 2015.

CASTRO, Joselma Salazar de. A docência na educação infantil como ato pedagógico. 2016.345 f. Tese (Tese em Educação) - Universidade Federal de Santa Catarina, Florianópolis, 2016. (mimeo)

CONTRERAS, José. Autonomia de professores. São Paulo: Cortez, 2002.

CORRÊA, Bianca; ANDRADE, Érika. Infância e vivências na educação infantil: qual o sentido das avaliações padronizadas nessa etapa educacional? Retratos da escola, Brasília, v. 5, n. 9, p. 275-289, jul./dez. 2011

CORSARO, William. Sociologia da infância. $2^{a}$ ed. Porto Alegre: Artmed, 2011.

EVANGELISTA, Olinda. Apontamentos para o trabalho com documentos de política educacional. 2009. Disponível em: http://www.dfe.uem.br/texto. Olinda. PDF. Acesso: em 11 de setembro de 2017.

FARIA, Ana Lúcia Goulart de. Educação pré-escolar e cultura. Campinas: Cortez/Editora da UNICAMP, 1999. 
FERREIRA, Manuela Maria. "Brincar às arrumações", arrumando ou... entre a ordem institucional adulto e a ordem institucional infantil, as crianças como actores sociais no jardim da infância. In: Reflexão e ação. v. 13, n. ${ }^{\circ}$ 1, jan./jun. Santa Cruz do Sul: UDUNISC, 2005. p. 115-132.

FREITAS, Luiz Carlos de. Blog do Freitas.BNCC: versão III para a educação infantil é criticada. São Paulo, 25 abr. 2017. Disponível em: https://avaliacaoeducacional.com/2017/06/23/educacao-infantilmec-paralisa-anei/. Acesso: em 05 de agosto de 2017.

FREITAS, Luiz Carlos de. Blog do Freitas.INEP inova na avaliação da educação infantil. São Paulo, 20 jun. 2015. Disponível em: https://avaliacaoeducacional.com/2017/06/23/educacao-infantil-mecparalisa-anei/. Acesso em 05 de agosto de 2017.

FREITAS, Luiz Carlos de. Blog do Freitas.Educação infantil: MEC paralisa ANEI. (Nota Pública) São Paulo, 23 jun. 2017. Disponível em: https:/ / avaliacaoeducacional.com/2017/06/23/educacao-infantilmec-paralisa-anei/. Acesso em 05 de agosto de 2017.

KRAMER, Sonia. Profissionais da educação infantil: gestão e formação. São Paulo: Ática, 2006.

MELLO, Suely Amaral. Infância e humanização: algumas considerações na perspectiva históricocultural. Perspectiva, Florianópolis, v. 25, n. 1. 83-104, jan/jun. 2007.

MORO, Catarina.Posicionamento sobre "Utilização/adoção de métodos e instrumentos padronizados de avaliação na primeira infância - aspectos convergentes e divergentes”. In: Utilização de métodos e instrumentos padronizados de avaliação na primeira infância: convergências e divergências. Fortaleza, 2016.

MORO, Catarina; SOUZA, Gisele. Produção acadêmica brasileira sobre avaliação em educação infantil:primeiras aproximações. Revista Est. Aval. Educ. São Paulo, v. 25, n. 58, mai./ago, 2014. p. 100-125. Disponível em: < http://www.fcc.org.br/pesquisa/publicacoes/eae/arquivos/1928/1928.pdf $\geq$. Acesso em: 15 ago. 2015.

NEVES, Vanessa Ferraz Almeida; MORO, Catarina. Avaliação na educação infantil: um debate necessário. Revista Est. Aval. Educ. São Paulo, v. 24, n. 55, abr./ago. 2013. Disponível em: <http://www.fcc.org.br/pesquisa/publicacoes/eae/arquivos/1821/1821.pdf>. Acesso em: 15 ago. 2015. p. 272-302. 
QVORTRUP, Jens. A infância enquanto categoria estrutural. Educação e Pesquisa, vol. 36, nº. 2, maiago, São Paulo: USP, 2010, p. 631-643.

ROCHA, Eloisa AciresCandal. A Pesquisa em Educação Infantil no Brasil: trajetória recente e perspectiva de consolidação de uma Pedagogia da Educação Infantil. Florianópolis: Centro de Ciências da educação, Núcleo de Publicações - NUP, 1999.

SARMENTO, Manuel Jacinto. Gerações e alteridade: interrogações a partir da sociologia da infância. In: Educação \& Sociedade, Campinas, v. 26, n. 91, ago. 2005. p. 361-378.

SAVIO, Donatella. A brincadeira e a participação da criança: um desafio educativo e seus pontos nodais. In: BONDIOLI, Anna; SAVIO, Donatella (Orgs.). Participação e qualidade em educação da infância: percursos de compartilhamento reflexivo em contextos educativos. Tradução: Luiz Ernani Fritoli. Curitiba: UFPR, 2013.

Il gioco e l'identità educativa del nido d'infanzia: un percorso di valutazione formativa pertecipativa nei nidi di Modena. Edizioni Junior srl. 1ª ed. Parma. 2011.

SOUZA, Fabrício Zimmermann.Plano de desenvolvimento da escola interativo: expressão da nova gestão pública na educação básica. 2015. 190 f. Dissertação (Mestrado em Educação) - Universidade Federal de Santa Catarina, Florianópolis, 2015.

SOUZA, G; MORO, C; COUTINHO, A.S. (org) Formação em Rede em Educação

Infantil: Avaliação de Contexto.Curitiba: Appris, 2015.

VIGOTSKI, Lev Semenovitch.El problema de laedad. Obras Escogidas. Tomo IV. Madrid: Centro de Publicaciones Del M.E.C. / Visor, 1996.

ZANARDINI, João Batista. Políticas de avaliação da educação pública. In: BATISTA, Alex Sandro dos Santos; EVANGELISTA, Olinda (Orgs). Políticas para a educação básica no Brasil. Florianópolis: UFSCCED-NUP, 2014. p. 67-114. 